\title{
Discussion on Folk Customs and Culture and Art of Architectural Decoration of Changle Academy Palace in Hakka Area
}

\author{
Zhenyu Li \\ Jiaying University Academy of Fine Arts \\ Meizhou, China 514015
}

\begin{abstract}
The author investigated the architectural space, architectural decoration and architectural components of Huacheng Changle Academy Palace in Wuhua County, Guangdong Province. The author made an observation and research on the main body of the building, such as Palace Wall Wanren, Ling Star Gate, Panchi, Halberd Gate, Dacheng Temple, East and West verandas etc, and made research on the accessorial building of space courtyard and the form of planting component as well as the decoration of architectural components, such as screens, cantilever, queti, column type, niches, short columns, etc. At the same time, in combination with relevant literature analysis and comparison, the author understood the atmosphere of Hakka culture and learned the local cultural connotation of academy palace in Hakka. By studying the Wuhua Huacheng Academy Palace architectural complex and its spatial arrangement design, and the artistic features of architectural decoration and garden layout, this paper makes discussion on how to inherit the ancient architectural culture and on how to protect, inherit, develop and innovate the Hakka traditional culture in the Hakka area in combination with the characteristics of Hakka area.
\end{abstract}

Keywords-Confucian culture; architectural decoration; folk auspicious blessing; pattern form

\section{INTRODUCTION}

Changle Academy Palace is located in Wuhua Middle School, Huacheng Cross Street, Wuhua County, Meizhou City, Guangdong Province. It was built in 1469 (the fifth year of Chenghua in Ming Dynasty). It was re-repaired in during Zhengde years, and rebuilt after the flood in 1867 (the sixth year of Tongzhi in Qing Dynasty). According to the ancient traditional style, the buildings are arranged on the central axis, symmetrical on the left and right, and on a large scale. According to the introduction of Wuhua Changle Academy Palace, the original architectural pattern of Changle Academy palace, from front to back, are Palace Wall Wanren, Ling Star Gate, Zhaobi, Panchi, Halberd Gate, East Verandas, West Verandas, Dacheng Temple, Minglun Hall , Zunjing Pavilion, etc., which is the largest and most characteristic Confucian Temple School with imperial palace style in Jiaying Prefecture. From the current situation, the Wanren Palace Wall, Ling Star Gate, Panchi, Halberd Gate, East Verandas, West Verandas, Dacheng Temple are still reserved. After the reform and opening up, Wuhua
County CPC Committee launched donations from all walks of life and repaired it according to its original appearance, so that the academy palace could shine again.

\section{THE FORMAL CHARACTERISTICS OF ARCHITECTURAL SPACE}

Changle Academy Palace now covers an area of 5100 square meters, sitting north and facing south, mainly composed of Wanren Palace Wall, Ling Star Gate, Panchi, Halberd Gate, East Verandas, West Verandas, Dacheng Temple and so on. In the open space in the palace are luxuriant but well-spaced bamboo and wood, where the grass looks like a green carpet, the buildings are decorated with auspicious carvings, poems and paintings; the solemn Dacheng Temple is equipped with statues of Confucius and other sages for worship. There are ancient imperial examination systems on display in the East Verandas, West verandas and Halberd Gate and wing rooms, which show the style of Wuhua, the inspirational stories of figures, and the introduction of the features.

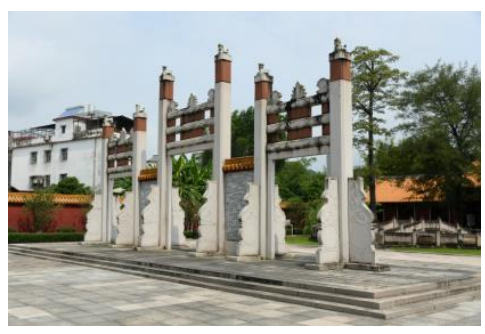

Fig. 1. Lingxing gate.

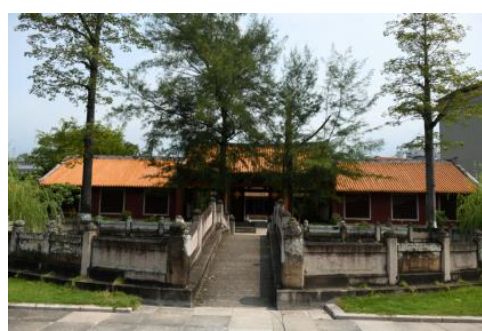

Fig. 2. Panchi and Halberd Gate. 


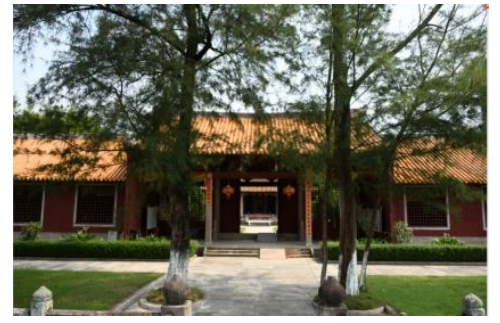

Fig. 3. Halberd Gate and Cypress in front of the door.

\section{A. Wanren Palace Wall}

The Wanren Palace Wall has now become creen walls facing the gate of a house, with the Ling Star Gate set to represent the formation of the boundary of Academy Palace, the Panchi set for the allusions of respecting Confucius and emphasizing education, and the Halberd Gate set for a kind of respect for Confucius Temple. Dacheng Temple is the space for memorial, worship and activities in the Confucius Temple. East and West verandas used to be a school, and now it is a place to show Wuhua Hakka's advocation of culture and emphasis on education and historical and cultural propaganda.

\section{B. Ling Star Gate}

Ling Star Gate is a kind of door of traditional Chinese ancient architecture, as shown in "Fig. 1", and it is made of archway wood or stone on the central axis of temple of literature. The ancient legend of Ling Star is literary star in the sky, this naming means that Confucius came to the world for the stars in the sky. It symbolizes that Confucius can be compared with Tianzhen star, which carries out enlightenment and widely cultivates talents in the sky.

\section{Ling Star}

Ling Star is also known as Tiantian star. As recorded in the book of the later Han Dynasty, Han Gaozu used it to worship heaven to pray for the year, and to make sacrifice to Tiantian star. Tiantian star is the left corner of "Dargon constellation", one of the 28 constellations, because the angle is the gate of the sky, the shape of the door is window lattice, so the door is called Ling Star gate. When the emperor sacrificed the heavens, he first sacrificed Ling star. Yuan Mei in the Essays in the garden said, "The descendants took the Han Ling star to pray for the year which has no relationship with Confucius Temple; later they saw the shape of the door as the window lattice, so changed it into Ling (lattice)". In the Song Dynasty, Ling star gate, also known as the Aconitum gate, was built in front of the temple of literature, symbolizing the Sacrificing Confucius as honoring the sky. The "Ling Star Gate" is an archway wood or stone building on the central axis of the temple of literature. The star gate in the temple of literature appeared fifteen years later Ming Taizu, Hongwu, symbolizing the Sacrificing Confucius as honoring the sky. As a result, people later interpreted the Ling Star as Tianzhen Star, Wen Qu Star, Kui Star. The ancients believed that "Star master of Tianzhen controls the celebration of winning scholars, whose essence is the god of the ling star", named the Ling star for Confucian Temple gate, It symbolizes that Confucius can be compared with Tianzhen Star, which carries out enlightenment and widely cultivates talents in the sky. It also means that scholars from all over the world gather here and unite under the door of Confucianism.

\section{Panchi, Panshui}

Panchi, Panshui, is the pool in front of the academy palace, as shown in "Fig. 2". Panlin is a forest by the water, Panshui was originally the water of Lupan Palace. For the "Pan", Zheng Yuanjian said in his Lu Song: "Pan means a half, half water covers the water in the south in the EastWest gate, and there is no water in the north". Pan is named because of the plane shape of the building. Panchi is located in front of the Dacheng Gate of the academic palace, which is a semicircle pool with straight outer circle and inner circle. In this way, Panchi became the pool of Pan Palace, and the later academy palace used this form. Panchi is the symbol of Confucius' thought "Kong Ze Liu Chang" and is the representative of local palace school. Later, admission was called "Entering Pan." In ancient China, Confucius always regarded "learning, with fortune in it" as the motto of scholars in pursuit of fame and wealth, because the imperial examination is the only way for scholars to enter the official career, and the title on the golden list means the beginning of a prosperous life. Therefore, the construction of academy palaces and of Panchi became the pursuit of fame and placed in study, so the advocation of culture and the emphasis on education became the system of schools in all regions.

\section{E. The Halberd Gate}

The Halberd Gate was originally made by the ancient emperors when they went out and put halberds in the place where they stayed. In Zhouli, Tianguan and Zhangshe, it is the Jimen of Tankuang palace. Zheng Xuan quoted the saying of Zheng Sinong of Han Dynasty as: "Jimen, with halberds as the door. In the Zi Zhi Tong Jian, the Third Year of Emperor Xizong's Reign of Tang Dynasty, it is said that "secretly gathered the troops 5000 people to enter the city, and killed Liang Zuan outside the halberd gate with the reason of not loyal for Gao's family but serving Qin Bi." $\mathrm{Hu}$ Sansheng noted: "according to the halberd system in the Tang Dynasty, there are twenty-four gates for the temple and the palace, among which eighteen gates for the East Palace, sixteen gates for the first grade, fourteen gates for the second grade, Jingzhao, Henan, Taiyuan Yin, Dadu, Daduhu, twelve gates for the third grade and Shangdudu, Zhongdudu, Shangdufu and Shangzhou, ten gates for the lower Dudu, lower Xiaduhu, Zhongzhou and Xiazhou respectively. The halberd is set in the door, called halberd door. "An extension refers to a house of dignitaries or a prominent official office. In $\mathrm{Ci} \mathrm{Hai}$, it is said: "a halberd is set in front of the door, which generally refers to the house of dignitaries". It can be seen that the establishment of halberd gate in front of the academy palace reflects the importance of the position of the academy palace. The stone arch bridge passes through the axis in the middle of Wuhua Panchi. Panchi is separated into two water surfaces from the middle, forming a shape like double eyes and becoming the 
eyes of the academy Palace. Halberd door, as shown in "Fig. 2", "Fig. 3", has a concave door structure, symmetrical on both sides of the square stone column, yellow glass tile roof, single eaves veranda hall top, with a single Hua arch and double lower Ang arch under the eaves; in the middle of the Halberd door is a wall, and in the wall is a screen or door; at both sides of the main wall are green square grid perforated glass windows, with a very large size, which is majestic; at both sides are the secondary house, lower than the main house Halberd door, symmetrical form on both sides of the winding unfold. Outside is the green square grid perforated glass window, with an obviously very large size, showing the overall grandeur and solemnity. Looking out from the inside of the halberd gate, the courtyard walls on both sides of the original halberd gate are replaced by the symmetrical distribution of slightly low secondary rooms. The decorations are all square mesh windows with vermeil background.

\section{F. The First Courtyard}

The first courtyard, between the Halberd Gate and the Dacheng Temple, is a large courtyard, and at the two sides of the courtyard are east-west verandas; in the middle is a modern slate road, with the stone lamp scattered along the arc; in the middle is a wide slate road, and at the end is a long incense case table placed in front of the Dacheng Temple; two incense stoves symmetrically are placed on both sides of the Dacheng Temple, with cypress trees on both sides and cycads embellished, and with an open lawn in the middle.

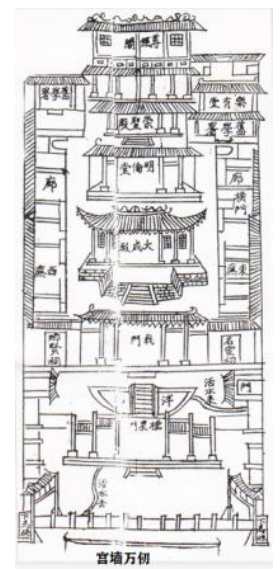

Fig. 4. Plane of Wuhua Academy Palace.

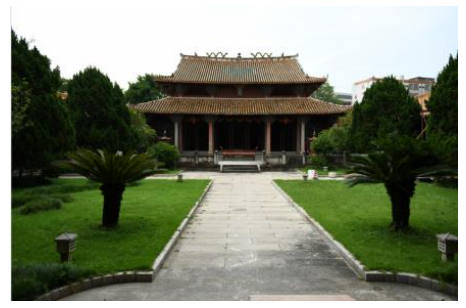

Fig. 5. Dacheng Temple.

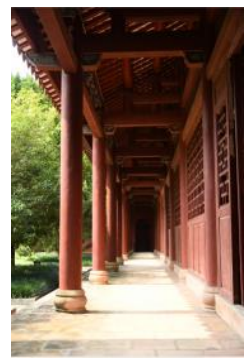

Fig. 6. Corridor of East-west verandas.

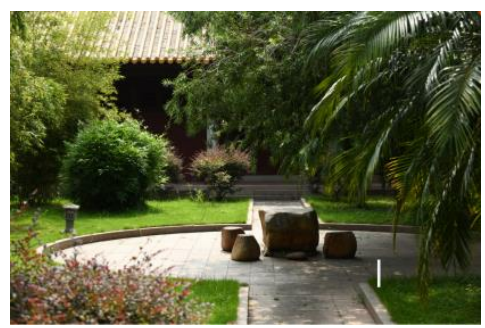

Fig. 7. Backyard stone table stool.

\section{G. Dacheng Temple}

Looking at the Dacheng Temple from the Halberd gate, through three steps, it is a transitional platform surrounded by stone railings; through a bronze tripod-like worship case on the middle axis, crossing two steps, and crossing the high threshold, it is the Dacheng Temple, as shown in "Fig. 5". Dacheng Hall is a double-eaved hip-roof building, with double Ang arch and bucket arch, five-room space, and with square stone columns supported; there is a half round porch structure in the front eaves, carved beams and painted rafters; in the middle is a spacious hall, with Confucius holy statue in the center, and with horizontal inscribed board of "Si Wen Zai Zi" and "Yv Tian Can Di"; the top board is inscribed as "Wan Shi Shi Biao" in the gold words; on both sides of the Confucius statue are holy statues of Mencius, Zisi, Zengzi and Yan Hui. The shrine is beautifully carved and golden and brilliant. Under the second layer of double eaves, there are “万”-pattern ventlights, symmetrically distributed on both sides. On the ridge, there are two symmetrical dragons, with lotus flowers in the middle and two fishes on the sidelines. There are more than ten stone pillars in the inner, the base is round and bulging, and the holy statue of Confucius is placed in the middle of the stone pillar. The stone column is a beam-lifting wooden structure, which plays the role of supporting and stabilizing the building. Different from the characteristics of all the wooden structures of the traditional building column bucket arch in the past, and here it has brought into full play the advantages of Wuhua people who are good at stone carving technology.

\section{H. The East-West Verandas}

In the corridor of the East and West verandahs, as shown in "Fig. 6", the outriggers and the two rafters at the secondary steps are extending to support the eaves. The arches are decorated with colorful grass patterns. The head 
of the beast is outstretched, and inward flower branches protrude, and with the red glass tile and the dripping water. Columns, perforated ventilation window, lattice grid pattern, skirt board, etc., are vermilion color, the white marble threshold is the basis of the gate. The column base is the white marble round beam waist protruding in the middle. In the West Wing veranda, as the main exhibition space of Wuhua historical celebrities, there are the statues of $\mathrm{Li}$ Huitang, the king of the world ball, the Qing Dynasty martial arts champion Li Weiguang, and the weapons and utensils he had used, as well as the events handed down, the photos of the former residence, etc., and there are also Wuhua Hakka traditional clothing, Han opera performances and other exhibitions and furnishings.

\section{The Second Courtyard}

After passing through the halberd gate, the corridor is surrounded by luxuriant forests of bamboos and cypresses. There are varieties of Osmanthus among them. On the middle axis, there are stone paved roads, dense railings on both sides, thick and simple lotus capitals. In the backyard of Dacheng Temple, there is a relatively modern rest scene, inadvertent stone table and four irregular stone benches, as shown in "Fig 7"; under the background of palm tree whirling and of bamboos and osmanthus trees swaying, it is bathed in the spring wind and fragrance.

\section{THE CHARACTERISTICS OF ARCHITECTURAL DECORATION ART}

\section{A. Simple Style of Tang and Song Dynasty}

The architectural form of halberd gate follows the architectural pattern and secondary building system since the time of Qufu Confucian Temple. The window decorations on the secondary rooms on both sides of the halberd gate facing south and back to north, follow the grid pattern since the Song Dynasty. The window decorations on the secondary rooms on both sides of the halberd gate facing south and back to north follow the grid pattern since the Song Dynasty, the concave belly gate has three-room space, and two square stone pillars support the wood beams of the three-opening rooms, the column type on the beam adopts the structure of bucket arch and double Ang arch. It has the style of Tang Dynasty, especially the extended double-Angarch type, which makes people laugh and be full of vitality. The drum-holding stone is placed in the corridor, and the three-step steps are the platform of the corridor for welcome.

\section{B. The Window and Screen Lattice Core Decoration}

The secondary windows on both sides of the halberd door are square checkered, as shown in "Fig.7". Screen lattice core is 井-pattern and miscellaneous pattern or vertical-bar half-window type. The decoration is simple and generous, and the pattern forms stretch continuously, implying long, long and continuous prospect.

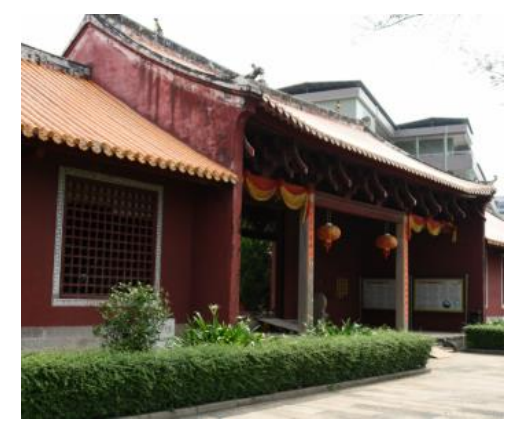

Fig. 8. Grid window with angled arches and trimmed hedges.

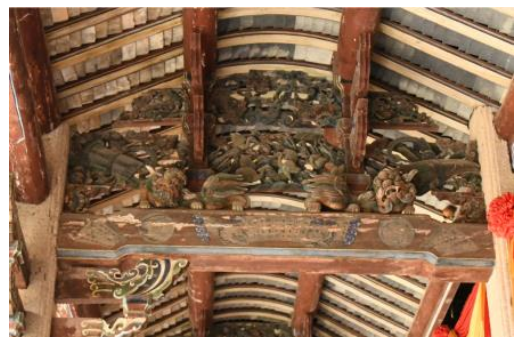

Fig. 9. Lion tuo pier on Hennessy Corridor.

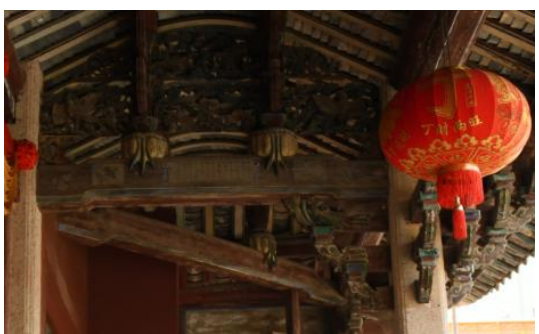

Fig. 10. Persimmon shaped melon column and bird and beast decoration.

\section{Folk Art of Praying for Blessings}

On the concave porch of Dacheng Temple, with stone pillars, there are two rafters interspersed, on which books, poems, gilded double lions and round carved pier described; on the piers are the figures of allusive eight immortals and cranes, as shown in "Fig. 8", which is a metaphor for the eight immortals offering birthday congratulations; around are peonies twined and wishful clouds pattern; on the top of the circular porch are two fierce beasts that show their teeth and roar up to the sky, with cloud pattern coiled; or in the middle is a vase, surrounded by peony painting and relievo, which is a metaphor for wealth, peace and prosperity; at the two sides are double phoenix surrounded and guarded, which is a metaphor for auspiciousness. The claw post is in the shape of persimmon, surrounded by wishful cloud patterns, which means that the building is solid and everything is wishful, as shown in "Fig. 9". The color of decoration is golden, green and blue, in a pure tinct and a strong contrast, and the image is full and exaggerated, and the color is rich. 


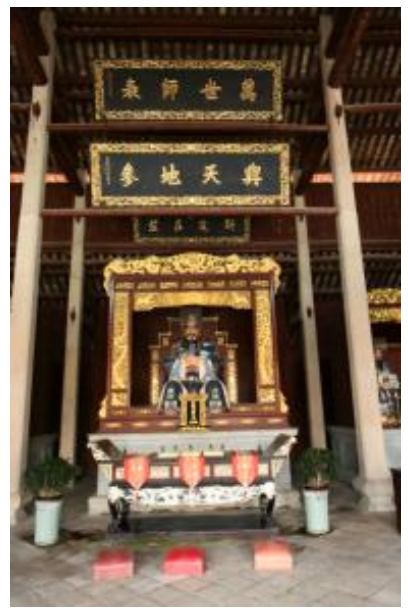

Fig. 11. The niches of Confucius.

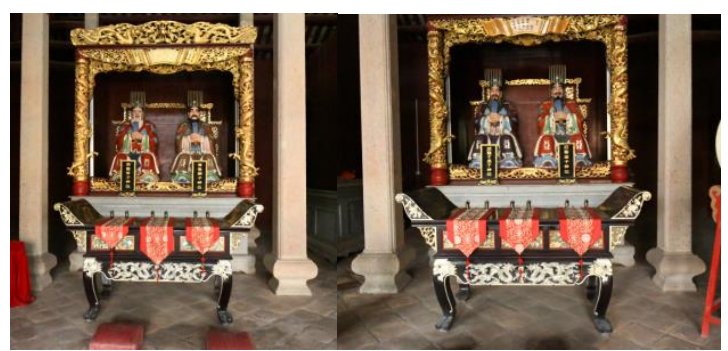

Fig. 12. The niches of Zengzi, Mencius, Zisi and Yanzi.

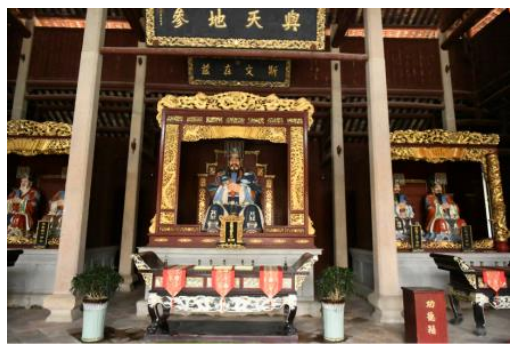

Fig. 13. The comparison of niches of Confucius and of other sages.

\section{Shrine Niche Decoration}

The niches of Confucius statues, as shown in "Fig. 10", adopts the form of hollow circular sculpture; there is a dragon sitting in the middle at the top, and two line dragons on each side. The two sides of the niche are embossed plant patterns with luxuriant foliage and flowers. On the Confucius statue, there is a scroll relief pattern, and on both sides of it are kylin auspicious animal relievo, and then the branches and leaves wrapped around. On both sides of the niche are two dragons circling; on the top of the niche are two dragons playing with beads; on the top of the sage's sculpture are relievo of the scroll; on both sides are two people exerting their strength to unfold the scroll; under and between the scroll are plant entwined with branches and openwork carvings of grapes, melons and fruits. The niches are decorated with gilding, and the tables are decorated with silver plating.

\section{E. Form of Confucius and Mencius Confucianism}

The architectural pattern of Wuhua Academy Palace, such as Wanren Palace Wall, Halberd Gate, Panchi, Dacheng Temple, East and West Verandas, and other architectural forms and layout basically continue the pattern of Confucius Temple, as shown in "Fig. 4". The halberd gate is relatively low; the Dacheng Hall has double eaves; Xieshan Temple is relatively high, and the East and West veranda rooms are relatively low, forming a pattern of ethics with high and low class order.

\section{F. Modern Decoration and Style}

In the academy palace, chimes or decorations are added. In the front of the Dacheng Temple, linear and rectangular censers are added, and tower shaped censers are added on the left and right sides. In the backyard of Dacheng Temple, there is a small rest space. Here, several irregular four stone benches and a stone table are placed, reflecting the style and form different from the traditional garden rules. The neatly trimmed hedge in front of the halberd gate reflects the characteristics of the modern western landscape design that the traditional natural hedge is broken by trimming, as shown in "Fig. 7".

\section{CONCLUSION}

Through the research on the spatial structure, decoration and garden of Wuhua Academy Palace, the following enlightenments are obtained: (1) the layout of the academy palace can at least adopts simple architectural forms such as Panchi, Halberd Gate, Dacheng Temple, East West verandas, etc. to form at least three front-yards and two court-yards, which are combined to present the traditional Chinese form; (2) the application of the forms of bucket arch, lifting beam, melon column, Tuo pier of double lions, flowers and birds, and the combination of stone column and bucket arch is different from the completely traditional architectural forms in the past, reflecting the characteristics of Hakka in praying culture and local culture; but when features are added, the whole traditional atmosphere won't be destroyed or lost; (3) In premise of keeping the traditional characteristics and the forms of buildings, the change of materials and the form of partial plant greening can still activate the environmental atmosphere of the whole academy palace; (4) the East-West verandahs have become a place to display and exhibit the Hakka culture of Wuhua. This has become an important significance for the existence of the modern academy palace, because it used to be a school, but now it has become a place for cultural relics and cultural protection and display; (5) too many other decorations, such as chimes and stone lamps that are too modern to imitate the past, may not appear in the scene of this building. To sum up, for the protection, inheritance and innovative development of ancient culture, it is necessary to follow and pursue the traditional forms and architectural styles of historical buildings in the past, so that historical building sites present the overall atmosphere of historical culture in the past. 


\section{REFERENCES}

[1] Introduction to Wuhua Changle academy palace. (in Chinese)

[2] Wu Weiguang, The iconographic significance of traditional residential building decoration - Taking the Hakka dragon house in East Guangdong as an example, Central China architecture, August 2008. (in Chinese)

[3] Lu Yuanding, Wei Yanjun. Guangdong folk house. China Construction Industry Press, 2018, 1. (in Chinese)

[4] Hou Youbin and Li Wanzhen. Map Theory of Ancient Chinese architectural history. China Construction Industry Press, 2002, 11. (in Chinese)

[5] Zhu Jinan. Interpretation of the source of Construction Law (1). China Construction Industry Press, 2013, 1. (in Chinese)

[6] Sun Dazhang. Research on Chinese folk houses. China Construction Industry Press, 2004, 8. (in Chinese)

[7] Zheng Jun and Xu Lihui. Auspicious China Atlas, happiness volume, Shanghai dictionary press. (in Chinese) 